$\begin{gathered}\text { Ana Dili Eğitimi Dergisi } \\ \text { Journal of Mother Tongue Education } \\ \text { www.anadiliegitimi.com }\end{gathered}$
Geliş/Received: 15.11 .2018 Kabul/Accepted:10.12.2018

\title{
Yabancı Dil Olarak Türkçe Öğretiminde Kaygı Üzerine Yapılan Araştırmaların İncelenmesi
}

\author{
Faruk POLATCAN*
}

Öz

$\mathrm{Bu}$ araştırmada yabancı dil olarak Türkçe öğrenenlerin kaygı durumlarına ilişkin çalışmalar incelenmiştir. Bu kapsamda 2018 yılına kadar yayımlanan 20 çalışmanın içerik analizleri yapılmıştır. İncelenen çalışmaların birçoğunda nicel ve ilişkisel model kullanııırken ölçme aracı olarak ise Horwitz, Horwitz ve Cope (1986) tarafından geliştirilen "Yabancı Dil Sınıf Kaygısı Ölçeği" çoğunlukla kullanılmıştır. Incelemeler sonucunda kadınların erkeklerden, dil düzeyi yüksek olanların daha düşük olanlardan, daha büyük yaş gruplarının 17 yaş altı gruptan daha fazla kaygı yaşadıkları belirlenmiştir. Çalışmaların çoğunlukla konuşma ve yazma dil becerilerine ilişkin olduğu görülmüştür. Araştırma sonucunda çalışmalarda; uygulamaya yönelik olarak hedef dilin günlük yaşamda kullanılabileceği ortamlar oluşturulmasına, kaygının eğitim sürecinde bir etken olarak kabul edilip ortamın bu anlayışla düzenlenmesine, sınıf içi çeşitli aktiviteler uygulanarak öğrencilerin kaygılarının giderilmesine ilişkin önerilerde bulunulmuştur. Çalışmalarda; araştırmacılara yönelik olarak ise farklı dil becerilerinde inceleme yapma, kaygıya ilişkin durum tespiti ve çözüm önerileri sunan araştırmaların yapılması ve hangi konularda konuşma kaygısı yaşandığının incelenmesine yönelik önerilerde bulunulmuştur.

Anahtar Kelimeler: Yabancı dil olarak Türkçe öğretimi, kaygı, dil becerileri, yabancı öğrenciler

\section{Examining the Researches on Anxiety in Teaching Turkish as a Foreign Language}

\begin{abstract}
In this study, studies on anxiety levels of learners of Turkish as a foreign language were examined. Within this context, content analyses of 20 studies published until 2018 were carried out. While quantitative and relational models were used in most of the examined studies, "Foreign Language Classroom Anxiety Scale", developed by Horwitz, Horwitz and Cope (1986) was applied as a measurement tool. As a result of the review, it was determined that anxiety levels are higher in females than males, in individuals who have high linguistic knowledge than those who have less linguistic knowledge and in older age groups than the younger groups (under 17 years old). It was found out that the studies were mostly related to speaking and writing language skills. As a result of the research, it was suggested that real and daily life situations in which target language can be used should be created to promote practice, anxiety should be taken into consideration in the learning process and the environment should be designed in accordance with considering it. Finally, students' anxiety should be eliminated by the help of several activities conducted in the classroom. In these researches, suggestions were made for the researchers to carry out analyses on different linguistic skills, to conduct researches on determining the level of anxiety and to offer solutions about this problem and to determine on which topics speaking anxiety was observed.
\end{abstract}

Keywords: Teaching Turkish as a foreign language, anxiety, language arts, foreign students

\footnotetext{
* Dr. Öğr. Üyesi, Sinop Üniversitesi, Türkçe ve Sosyal Bilimler Eğitimi Bölümü, Sinop, farukpolatcan@gmail.com, ORCID: 0000-0002-6897-8932
} 


\section{Giriş}

Türkçe; bilinen tarih boyunca ticaret, savaşlar, dinleri yayma faaliyetleri vb. nedenlerle ilişkide bulunulan toplumlarca yabancı dil olarak öğrenildiği söylenebilir. Günümüzde ise devlet desteğiyle modern anlamda yabancılara Türkçe öğretimi yapılmaktadır. Yurt içinde üniversitelerin dil öğretimi merkezleri, yurt dışında ise Yunus Emre Enstitüsü, Türkiye Maarif Vakfı ve birçok yabancı üniversitedeki Türkoloji bölümleri tarafından Türk dili ve kültürü öğretilmektedir. Türkiye'de veya dünyanın farklı bölgelerinde Türkçe öğrenenlerin öğrenmelerini etkileyen birçok unsur bulunmaktadır. Bu unsurlardan biri de kaygıdır (Erdil, 2016; Halat, 2015; Özdemir, 2013; Rashid, 2017).

Kaygı, "üzüntü, endişe duyulan düşünce, tasa"dır (Türk dil Kurumu [TDK], 2011: 1363). Polatcan (2018) yabancı dil öğrenmede kaygıyı "başarısızlık duygusu nedeniyle kişinin kabuğuna çekilmesi" (s. 37) olarak tanımlamaktadır. Kaygının öğrenme üzerindeki etkisine ilişkin farklı değerlendirmeler bulunmaktadır. Kleinmann (1977) kaygı seviyeleri yüksek olan öğrenenlerin konuşma ve yazma dil becerilerinde daha zor, karmaşık olarak nitelendirilebilecek gramer yapılarını kullandıklarını belirtmiştir. Buna karşın Sparks ve Ganschow (1991) ise kaygı seviyesi yüksek öğrenenlerin hem ana dillerini hem de hedef dilleri yeterince bilmediklerini vurgulamışlardır. Dil yetisi yeterli düzeye ulaşamayan bireylerin iletişimde kaygı yaşamaları kaçınılmaz bir gerçekliktir. Bunun yanı sıra sınavlar da kaygının önemli nedenlerinden biridir. Değerlendirilme fikri her hangi bir konuda her bireyde olduğu gibi yabancı dil öğrenenleri de kaygılandıran önemli etkenlerin başında gelmektedir. Yoğurtçu ve Yoğurtçu (2013) tarafından yapılan araştırma sonuçlarına göre yabancı dil olarak Türkçe öğrenenlerden sınav sonuçları başarısız olanların Türkçe öğrenme kaygılarının diğerlerinden daha yüksek olduğu anlaşılmaktadır. Erdil (2016) yabancı dil öğrenme kaygısı ile öğrencilerin cinsiyet, yaş, geldikleri ülke, ana dil, bildikleri yabancı dil sayısı, Türkiye'ye gelme sebebi ile Türkçe öğrenme amacı arasında anlamlı ilişki bulunmadığını belirlemiştir.

Altunkaya (2017) yabancı dil öğrenenlerin dinleme ve okuma becerilerine ilişkin kaygı düzeylerinin orta seviyede olduğunu belirlemiştir. Bunun yanı sıra araştırmada yaş, cinsiyet ve Türkçe öğrenim süresi değişkeni ile öğrencilerin dinleme ve okuma kaygı düzeyleri arasında anlamlı bir ilişki bulunamamıştır. Altunkaya ve Erdem (2017) okuma kaygısı ile okuma başarısı arasında ters yönlü ilişki olduğunu belirlemişlerdir. Halat (2015) yabancı dil öğrenenlerin dinleme kaygıları ile cinsiyet, yaş, eğitim düzeyi, bildikleri yabancı dil sayısı durumları arasında anlamlı ilişki bulunmadığını tespit etmiştir.

Konuşma kaygısı ile öğrencilerin yaşları, cinsiyetleri, dil düzeyleri, meslekleri ve daha önce Türkiye'de bulunup bulunmama durumları arasında anlamlı bir ilişki bulunmamaktadır (Boylu ve 
Çangal, 2015). Yabancı dil olarak Türkçe öğrenenlerden daha büyük yaş grubundakiler küçük yaş grubundakilerden daha fazla konuşma kaygısı taşımaktadırlar. Bu duruma karşın öğrencilerin cinsiyet, ana dili ve bildikleri diğer yabancı dil değişkenlerinin Türkçe konuşma kaygıları üzerinde herhangi bir etkisi bulunmamaktadır (Özdemir, 2013). Türkçe öğrenen yabancı öğrencilerin cinsiyet ve dil düzeyi değişkenleri ile konuşma kaygıları arasında anlamlı bir ilişki bulunmazken iyi bir iş bulmak için Türkçe öğrenenler yabancılarla iletişim kurmak için Türkçe öğrenenlere göre daha fazla konuşma kaygısı taşımaktadırlar (Rashid, 2017). Yabancı dil olarak Türkçe öğrenenlerden Türkçenin zor bir dil olduğunu söyleyenler diğerlerine göre daha fazla konuşma kaygısı taşımaktadırlar (Sallabaş, 2012). Yabancı dil olarak Türkçe öğrenmek isteyen İranlı öğrenenlerin cinsiyet, yaş, eğitim durumları, dil düzeyleri, Türkçe yayın yapan televizyonları dinleme sıklıkları ve Türkçe müzik dinleme sıklıkları değişkenleri ile konuşma kaygıları arasında anlamlı bir ilişki bulunmamaktadır (Şen ve Boylu, 2015).

İşcan (2015) yabancı dil olarak Türkçe öğrenen Ürdünlü öğrencilerin kompozisyonlarının olumsuz değerlendirileceği korkusu, zaman sınırlaması ve öz güven eksikliği nedeniyle yazma kaygı düzeylerinin yüksek olduğunu belirlemiştir. Yabancı öğrenciler yazarken uyrukları, alfabe farklııkları ve okuma alışkanlıkları nedeniyle çoğunlukla kaygı duymaktadırlar (Maden, Dincel ve Maden, 2015). Yabancı dil olarak Türkçe öğrenenlerden Ural Altay dil ailesi mensubu olanlar; Hint Avrupa, Bantu ve Sami dil aileleri mensubu olanlardan daha az yazma kaygısı taşımaktadırlar (Polatcan, 2016).

Özellikle son on yılda terör, işsizlik, siyasi istikrarsızlık, otoriter devlet yönetimlerinin etkisiyle yüz binlerce insan vatanlarından uzakta yaşamak durumunda kalmıştır. Hem göç edilen yollar üzerinde bulunması hem de göç edilmek istenen ülke olması nedeniyle günümüzde Türkiye'de çok sayıda göçmen bulunmaktadır. Türkiye'nin küresel bir güç olmaya başlaması ve ülkede göçmen sayısının artması nedeniyle her yıl binlerce insan Türkçe öğrenmektedir. Dil öğrenmeyi pek çok nedenle birlikte öz güven, kaygı, istek vb. psikolojik faktörler de etkilemektedir. Bu çalışmada yabancı dil olarak Türkçe öğrenenlerin kaygı durumlarını ayrıntılı bir şekilde belirlemek amaçlanmıştır. Bu amaç çerçevesinde aşağıdaki sorulara cevap aranmıştır.

- Araştırmaların dil becerilerine dağılımı nasıldır?

- Araştırmaların yöntem ve desenlere dağılımı nasıldır?

- Araştırmaların örneklemlerine ilişkin dağılım nasıldır?

- Araştırmalarda kullanılan ölçme araçlarının dağılımı nasıldır?

- Araştırmaların demografik değişkenlere dağılımı nasıldır?

- Yabancı dil olarak Türkçe öğretiminde kaygıya ilişkin nitel araştırmaların dağııımı nasıldır? 
- Yabancı dil olarak Türkçe öğretiminde kaygıya ilişkin araştırmaların araştırmacılara ve uygulayıcılara önerileri nelerdir?

\section{Yöntem}

$\mathrm{Bu}$ araştırmada içerik analiz türlerinden meta sentez kullanılmıştır. Meta sentez, bir konu üzerine yapılan araştırmaların genel özelliklerinden yola çıkarak -sorgulayıcı bir anlayışla-sentezlenip yorumlanmasıdır. Meta sentez, araştırmalara ulaşamama, iş yükü $v b$. nedenlerle eğitim araştırmalarındaki gelişmeleri takip edemeyen araştırmacılara ve öğretmenlere önemli kolaylıklar sağlar (Çalık ve Sözbilir, 2014: 34-36). Meta sentez, tek tek ulaşılan araştırma sonuçlarından yola çıkarak fikirlerin ve temaların birleştirilmesine imkân vermektedir (Welch, 2008). Bu araştırmada araştırmacılar tarafından yabancı dil olarak Türkçe öğrenenlerin kaygı durumlarıyla ilgili çalışmaların nasıl bir eğilime sahip olduğunun nitel yöntemlerle analiz edilmesi amaçlandığından meta sentez kullanılmıştır.

Meta sentez çalışmalarının sistematik olabilmesi için üç özelliğe sahip olması gerekir. Bu özellikler şunlardır:

- Çalışmaların seçimi için kriterlerin açıkça belirtilmesi gerekir.

- Araştırma bulguları genel değerlendirmeye tutulmamalıdır. Her araştırmadan elde edilen bulgular tek tek değerlendirmeye tabi tutulmalıdır.

- Araştırmaları değerlendirebilmek için kodlama listesi tutulmalıdır (Norris ve Ortega, 2007).

Verilerin Analizi ve Çalışmaların Araştırmaya Dâhil Edilme Kriterleri

Araştırmaların sistematik olabilmesinin ilk şartı olan çalışmaların seçilme kriterleri belirlenmiştir. Bu aşamada çalışmalarda; (i) yabancılara Türkçe öğretimi alanındaki tam metin ampirik makalelerden oluşması, (ii) Eric, TR Dizin, EBSCO, Türk Eğitim İndeksi, Google Akademik arama motoru ve Yüksek Öğretim Kurulu Tez Merkezi veri tabanlarından taranmış olması, (iii) özgün yayınlar olması, (iv) yabancılara Türkçe öğretiminde kaygıya yönelik olması özellikleri aranmıştır. Çalışmaların tamamının son altı yılda yapılması nedeniyle yıl özelinde herhangi bir sınırlamaya gidilmemiştir.

\section{Veri Toplama ve Analizi Süreci}

Araştırma kriterlerine bağlı olarak veri toplayabilmek için bir değerlendirme formu hazırlanmıştır. Hazırlanan bu form aracılığıyla araştırmacı tarafından belirlenen veri tabanlarında çalışmalar taranmıştır. Ulaşılan çalışmalar bilgisayar ortamına kaydedilerek Ç1, Ç2, Ç3... Ç20 olarak kodlanmıştır. Sonraki aşamada Microsoft Office Word programıyla çalışmaların yayın türleri, dil becerilerine dağılımları, yöntem ve desenleri, örneklem dağılımları, kullanılan ölçme araçları, demografik değişkenleri, araştırmacılara ve uygulayıcılara yönelik öneriler kategorilere ayrılmıştır. 
Üçüncü aşamada ise değerlendirmeler yapılarak ortak temalara ulaşılmaya çalışılmıştır. Çalışmalar hazırlanan form doğrultusunda iki kodlayıcı tarafından kodlanmıştır. Son aşamada formlar birleştirilerek ortak bir form elde edilmiştir.

\section{Bulgular}

Bu bölümde araştırmaların yayın türlerine, hangi dil becerisiyle ilgili olduklarına, yöntemine, örneklem büyüklüklerine, demografik değişkenlerine ve araştırmalarda kullanılan / geliştirilen ölçme araçlarına, yabancı dil olarak Türkçe öğretiminde kaygıya ilişkin nitel araştırmaların dağılımına, uygulamaya ve araştırmacılara yönelik ortak önerilere yer verilmiştir.

Tablo 1. Araştırmaların yayın türlerine dağılımı

\begin{tabular}{lcc}
\hline Yayın Türleri & $\boldsymbol{f}$ & $\boldsymbol{\%}$ \\
\hline Doktora Tezi & 1 & 5 \\
Yüksek Lisans Tezi & 4 & 20 \\
Makale & 15 & 75
\end{tabular}

Tablo 1'de görüldüğü üzere araştırmada incelenen yayınların çoğu makalelerden oluşmaktadır. Yabancı dil olarak Türkçe öğretiminde kaygı üzerine doktora çalışması olarak yalnızca 1 araştırma bulunurken yüksek lisans tezi olarak 4, makale olarak 15 araştırma bulunmaktadır.

Tablo 2. Araştırmaların dil becerilerine dağııımı

\begin{tabular}{lccc}
\hline Dil Becerisi & $f$ & $\%$ \\
\hline Konuşma & 8 & 36.36 \\
Yazma & 5 & 22.72 \\
Okuma & 3 & 13.63 \\
Dinleme & 2 & 9.09 \\
Genel & 4 & 18.18 \\
\hline
\end{tabular}

Tablo 2'de görüldüğü gibi çalışmaların dil becerilerine dağıımı sırasıyla konuşma (f: 8), yazma (f: 5), genel (f: 4), okuma (f: 3) ve dinlemeden (f: 2 ) oluştuğu görülmektedir. Çalışmalarda çoğunlukla konuşma ve yazma dil becerilerinin araştırma konusu olarak seçildiği görülmüştür. Diğer taraftan okuma ve dinleme dil becerilerinin sıklıkla araştırımadığı anlaşılmaktadır.

Tablo 3. Araştırmaların yöntem ve desenlere dağılımı

\begin{tabular}{|c|c|c|c|}
\hline Yöntem & Desen & $f$ & $\%$ \\
\hline \multirow{3}{*}{ Nicel } & Tarama & 10 & 50 \\
\hline & İlişkisel & 3 & 15 \\
\hline & Deneysel & 1 & 5 \\
\hline Nitel & Durum & 1 & 5 \\
\hline \multirow{2}{*}{ Karma } & Eş zamansız & 4 & 20 \\
\hline & Tarama & 1 & 5 \\
\hline
\end{tabular}


Tablo 3'te görüldüğü üzere araştırmada incelenen çalışmaların çoğunluğunda nicel yöntemler kullanılmıştır. Nicel yöntemlerin kullanıldığı çalışmalarda çoğunlukla tarama (f: 10) çalışmaları yapılmıştır. Nitel yöntemle yapılan araştırmada durum deseni kullanılmıştır. Nicel ve nitel yöntemlerin birlikte kullanıldığı karma çalışmalarda en fazla eş zamansız desen kullanıımıştır.

Tablo 4. Araştırmaların örneklemlerine ilişkin dağılım

\begin{tabular}{llc}
\hline Örneklem Grubu & $f$ & $\%$ \\
\hline $50-100$ & 10 & 50 \\
$101-150$ & 6 & 30 \\
$>150$ & 4 & 20 \\
\hline
\end{tabular}

Tablo 4'te görüldüğü üzere araştırmaların büyük çoğunluğu (f: 10) örneklem sayısı 100'ün altında olduğu görülmüştür. Örneklem grubu 150 üzeri olan çalışma sayısı yalnızca 4’tür.

Tablo 5. Araştırmalarda kullanılan ölçme araçlarının dağılımı

\begin{tabular}{llc}
\hline Kullanılan ölçme araçları & $f$ & $\%$ \\
\hline Yabancı Dil Sınıf Kaygısı Ölçeği (Horwitz, Horwitz ve Cope, 1986) & 5 & 27.77 \\
İkinci Dil Konuşma Kaygısı Ölçeği (Melanlığlu ve Demir, 2013) & 11.11 \\
Yabancı Dil Olarak Türkçe Öğrenenlere Yönelik Okuma Kaygısı Ölçeği (Altunkaya ve & 2 & 11.11 \\
Erdem, 2016) & 1 & 5.55 \\
İkinci Dilde Yazma Kaygısı Ölçeği (SLWAı) (Cheng, 2004) & 1 & 5.55 \\
Konuşma Kaygısı Ölçeği (Özdemir, 2013) & 1 & 5.55 \\
Yabancı Dil Kaygı Ölçeği (Doğan, 1988) & 1 & 5.55 \\
Yabancı Dil Öğrenme Kaygısı Ölçeği (Baş, 2013) & 1 & 5.55 \\
Yabancı Dil Dinleme Kaygısı Ölçeği (Kim, 2002) & 1 & 5.55 \\
Türkçeyi Yabancı Dil Olarak Öğrenenlere Yönelik Yazma Kaygısı Ölçeği & 1 \\
Yazma Kaygısı Ölçeği & 1 & 5.55 \\
Türkçeyi Yabancı Dil Olarak Öğrenenlerin Konuşma Kaygılarının Kaynakları Ölçeği & 1 & 5.55 \\
Konuşma Kaygısı Ölçeği & 1 & 5.55
\end{tabular}

Tablo 5'te görüldüğü gibi çalışmalarda en fazla kullanılan ölçme aracı Horwitz, Horwitz ve Cope (1986) tarafından geliştirilen Yabancı Dil Sınıf Kaygısı Ölçeğidir (f: 5). Melanlıoğlu ve Demir'in (2013) İkinci Dil Konuşma Kaygısı Ölçeği ile Altunkaya ve Erdem'in (2016) Yabancı Dil Olarak Türkçe Öğrenenlere Yönelik Okuma Kaygısı Ölçeği ise 2'şer defa kullanılmıştır.

Tablo 6. Araştırmaların demografik değişkenlere dağılımı

\begin{tabular}{llcc}
\hline Değişkenler & Sonuç & $f$ & $\%$ \\
\hline \multirow{2}{*}{ Cinsiyet } & Fark var & 1 & 14.29 \\
& Fark yok & 6 & 85.71 \\
\hline \multirow{2}{*}{ Yaş } & Fark var & 1 & 20 \\
& Fark yok & 4 & 80 \\
\hline \multirow{2}{*}{ Dil düzeyi } & Fark var & 2 & 50 \\
& Fark yok & 2 & 50 \\
\hline
\end{tabular}


Tablo 6'da öğrenenlerin yabancı dil olarak Türkçe öğrenme kaygılarının bazı demografik değişkenlere ilişkin sonuçları incelenmiştir. Cinsiyet değişkeni açısından yabancı dil öğrenenlerin kaygılarının farklılaşmadığını ortaya koyan çalışmalar çoğunluktadır (f: 6). Yaş değişkeni açısından da yabancı dil öğrenenlerin kaygılarının farklılaşmadığı sonucuna ulaşan çalışmalar çoğunluktadır (f: 4). Dil düzeyi değişkeni açısından yabancı dil öğrenenlerin kaygılarının farklılaşmadığını ortaya koyan çalışmalar (f: 2 ) ile farklılaştığını (f: 2) belirten çalışmalar eşit sayıdadır.

Tablo 7. Yabancı dil olarak Türkçe öğretiminde kaygıya ilişkin nitel araştırmaların dağııımı

\begin{tabular}{lcc}
\hline Alt Tema & $f$ & $\%$ \\
\hline Yabancı dil olarak Türkçe öğrenme kaygısını etkileyen çeşitli değişkenler & 3 & 50 \\
Yabancı dil olarak Türkçe konuşma kaygısını etkileyen çeşitli değişkenler & 2 & 33.33 \\
Yabancı dil olarak Türkçe dinleme kaygısını etkileyen çeşitli değişkenler & 1 & 16.66 \\
\hline
\end{tabular}

Tablo 7'de yabancı dil olarak Türkçe öğrenenlerin öğrenme kaygılarını hatalara odaklanılması, deyimleri hatırlamama / yanlış hatırlama, eğitim kaygısı, telaffuz sorunları etkilemektedir (f: 3 ). Yabancı dil olarak Türkçe öğrenenlerin konuşma kaygılarını yabancı insanlarla ilk tanışma durumu, öğrencilik profilleri, dikkat toplama - odaklanabilme, hazırlıksız konuşma durumu, kişilik profilleri, ana dili farkı birisi ile konuşma durumu, yabancı dil öğrenimine ilişkin motivasyon $v b$. değişkenler etkilemektedir (f: 2). Yabancı dil olarak Türkçe öğrenenlerin dinleme kaygılarını bilinmeyen sözcükler, hızlı konuşma, farklı dil bilgisi yapısının etkilediği belirlenmiştir (f: 1).

Çalışmalarda uygulamaya ve araştırmacılara yönelik çeşitli öneriler yapıldığı tespit edilmiştir. $\mathrm{Bu}$ öneriler aşağıdaki tablolarda sunulmuştur.

Tablo 8. Araştırmalarda uygulamaya ilişkin öneriler

\begin{tabular}{lcc}
\hline Öneriler & $f$ & $\%$ \\
\hline Hedef dilin günlük yaşamda kullanılabileceği ortamlar oluşturulması & 5 & 17.24 \\
Kaygının eğitim sürecinde bir etken olarak kabul edilip ortamın bu durum dikkate & 5 & 17.24 \\
alınarak düzenlenmesi & & \\
Sınıf içi çeşitli aktiviteler uygulanarak öğrencilerin kaygılarının giderilmesi & 4 & 13.79 \\
Illgi düzeyine ve güdülemeye dikkat edilmesi & 4 & 13.79 \\
Öğrencilere profesyonel rehberlik yapılması & 3 & 10.34 \\
Sınıf içi konuşma uygulamalarına daha çok yer verilmesi & 2 & 6.89 \\
Öğrencilerin cesaretlendirilerek kaygı düzeylerinin düşürülmesi & 2 & 6.89 \\
Günlük yaşamdaki intiyaçların dikkate alınması & 1 & 3.44 \\
Öğrencilerin okumaya teşvik edilmesi & 1 & 3.44 \\
Sınıfların bilinen dil sayıları göz önüne alınarak düzenlenmesi & 1 & 3.44 \\
Yazma ile ilgili sık sık uygulama çalışmalarının yapılması & 1 & 3.44 \\
\hline
\end{tabular}


Tablo 8'de görüldüğü gibi çalışmalarda yabancılara Türkçe öğretiminde kaygı ile ilgili uygulamaya yönelik olarak hedef dilin günlük yaşamda kullanılabileceği ortamlar oluşturulması (f: 5), kaygının eğitim sürecinde bir etken olarak kabul edilip ortamın bu durum dikkate alınarak düzenlenmesi (f: 5), sınıf içi çeşitli aktiviteler uygulanarak öğrencilerin kaygılarının giderilmesi (f: 4) ile ilgi düzeyine ve güdülemeye dikkat edilmesine (f: 4) ilişkin öneriler yoğunluktadır.

Tablo 9. Araştırmalarda araştırmacılara yönelik öneriler

\begin{tabular}{llc}
\hline Öneriler & $f$ & $\%$ \\
\hline Farklı dil becerilerinde inceleme & 3 & 17.64 \\
Kaygıya ilişkin durum tespiti ve çözüm önerileri sunan araştırmaların yapııması & 2 & 11.76 \\
Hangi konularda konuşma kaygısı yaşandığının incelenmesi & 2 & 11.76 \\
Farklı dil öğretim merkezlerinde benzer çalışmaların yapılması & 1 & 5.88 \\
Sınıfların dil aileleri dikkate alınarak oluşturulması & 5.88 \\
Farklı dil düzeylerinde yapılan araştırmaların karşılaşırılması & 5.88 \\
Okuma ve dinleme kaygısı ile okuduklarını ve dinlediklerini anlama düzeyleri & 1 & 5.88 \\
arasındaki ilişkinin araştırılması & 1 & 5.88 \\
Yazma kaygısının nedenleri üzerine incelemelerin yapılması & 1 & 5.88 \\
Konuşma kaygısının nedenleri üzerine incelemelerin yapılması & 1 & 5.88 \\
Kaygı ile dil öğrenme düzeylerinin ilişkisinin araştırılması & 1 & 5.88 \\
Çevrenin kaygı üzerindeki etkisinin incelenmesi & 1 & 5.88 \\
Ortamın kaygı üzerindeki etkisinin incelenmesi & 1 & 5.88 \\
Kaygının farklı psikolojik etmenler ile ilişkisinin incelenmesi & 1 & 5
\end{tabular}

Tablo 9'da yabancı dil olarak Türkçe öğretiminde kaygıya ilişkin yapılan araştırmalarda araştırmacılara önerilerin çoğunlukla farklı dil becerilerinde inceleme, kaygıya ilişkin durum tespiti ve çözüm önerileri sunan araştırmaların yapılması ve hangi konularda konuşma kaygısı yaşandığının incelenmesi üzerine yoğunlaştığı görülmektedir.

\section{Sonuç ve Öneriler}

Bu araştırmada yabancılara Türkçe öğretiminde kaygı kavramına ilişkin araştırmaların içerik bakımından analiz edilmesi amaçlanmıştır. Araştırmalar incelenirken araştırmaların dil becerilerine dağılımı, yöntem ve desenleri, örneklemleri, kullanılan ölçme araçları, demografik değişkenleri, nitel temaları ve temalar sonucunda araştırmacıların araştırmacılara ve uygulayıcılara önerileri ortaya çıkarılmıştır.

Yapılan araştırmaların çoğunlukla konuşma dil becerisiyle (f: 8) ilgili olduğu görülmüştür. Dil öğrenmenin genellikle konuşma becerisiyle eş tutulması nedeniyle araştırmaların çoğunlukla konuşma dil becerisiyle ilgili olduğu söylenebilir. Bunun yanı sıra Türkçenin tarihi kaynaklarıyla ilgili yapılan çalışmalarda (Çoban, 2013; Şahin, 2012) konuşma dil becerisine ilişkin kavram işareti sayısının 
daha fazla olduğu belirlenmiştir. Bu sonuçlardan Türk milletinin konuşma dil becerisine diğer becerilerden daha çok önem verdiği / konuşma becerisini daha çok kullandığı söylenebilir.

Araştırmada incelenen çalışmaların çoğunluğunda nicel (f: 15) araştırma yöntemlerinin kullanıldığı, nitel ve karma yöntemle yapılan araştırmaların sayıca yetersiz olduğu görülmüştür. Nicel yöntemle yapılan araştırmaların genellenebilir olması nedeniyle daha fazla kullanıldığı söylenebilir. Cresvell (2016) araştırma bulgularının sayısal verilerle kullanılabilmesi nedeniyle nicel yöntemlerin sıklıkla kullanıldığını vurgulamıştır.

Yabancılara Türkçe öğretiminde kaygıyla yapılan araştırmaların tamamının Türkçe öğrenen yabancı öğrencilere uygulandığı ve örneklem büyüklüğünün çoğunlukla 50-100 arası olduğu saptanmıştır. Konuyla ilgili uygulayıcıların ve teorisyenlerin içinde bulunduğu herhangi bir çalışmaya rastlanılmamıştır. Öte yandan yabancılara Türkçe öğretiminde kaygıyla ilgili yapılan araştırmalarda çoğunlukla ölçeklerin kullanıldığı / geliştirildiği görülmüştür. Araştırmalarda Horwitz, Horwitz ve Cope (1986) tarafından geliştirilen "Yabancı Dil Sınıf Kaygısı Ölçeği” yaygın olarak kullanılmıştır. Yabancı dil öğrenmenin evrensel bir konu olması nedeniyle bilim dünyasında çokça bilinen ölçeğin araştırmalarda ölçme aracı olarak kullanıldığı düşünülmektedir.

Araştırmalarda Türkçe öğrenen yabancı öğrencilerin kaygı durumlarına ilişkin olarak cinsiyet, yaş ve dil düzeyleri gibi demografik değişkenlerin incelendiği görülmüştür. Araştırmalarda yabancı dil olarak Türkçe öğrenenlerin cinsiyet ve yaşlarının kaygıyla ilişkili olmadığını gösteren (Altunkaya, 2017; Erdil, 2016; Halat, 2015; Şen ve Boylu, 2015) çalışmaların daha çok olduğu görülürken dil düzeyi değişkeninin kaygıyla olumlu ve olumsuz ilişkisine dair eşit sayıda çalışma olduğu belirlenmiştir. Kadın ve erkek öğrenciler arasında yabancı dil kaygı düzeyi açısından anlamlı fark bulunmamasına karşın kadın öğrenciler erkek öğrencilerden daha fazla kaygılıdırlar (Sarıgül, 2000). Batum ve Erden (2007) eğitim sürecinde C dil düzeyindeki öğrencilerin B dil düzeyindeki öğrencilere göre daha kaygılı olduklarını tespit etmişlerdir.

Yabancı dil olarak Türkçe öğrenenlerin kaygı durumlarına ilişkin yapılan araştırmalarda uygulamaya yönelik olarak hedef dilin günlük yaşamda kullanılabileceği ortamlar oluşturulmasına, kaygının eğitim sürecinde bir etken olarak kabul edilip ortamın bu duruma uygun düzenlenmesine, sınıf içi çeşitli aktiviteler uygulanarak öğrencilerin kaygılarının giderilmesine ve ilgi düzeyine ve güdülemeye dikkat edilmesine ilişkin öneriler sıklıkla yapılmıştır. Yabancı dil olarak Türkçe öğrenenlerin kaygı durumlarına ilişkin araştırmacılara yönelik olarak farklı dil becerilerinde inceleme yapma, kaygıya ilişkin durum tespiti ve çözüm önerileri sunan araştırmaların yapılması ve hangi konularda konuşma kaygısı yaşandığının incelenmesine yönelik önerilerde bulunulmuştur. 
Bu sonuçlar ışı̆̆ında araştırıcılara şu önerilerde bulunulabilir:

- Yabancı dil olarak Türkçe öğrenenlerin kaygı durumlarına yönelik araştırmalarda nicel araştırmaların hâkim olduğu, nitel ve karma araştırmaların yeterince yapılmadığı anlaşılmıştır. Konuyla ilgili nicel araştırmalara ek olarak nitel araştırmalar da yapılabilir.

- Araştırmaların çoğunlukla konuşma ve okuma dil becerileriyle ilgili olduğu görülmüştür. Konuyla ilgili yazma ve dinleme dil becerilerine ilişkin daha fazla çalışma yapılabilir.

\section{Kaynaklar}

Altunkaya, H. (2017). Yabancı dil olarak Türkçe öğrenenlerin dinleme ve okuma kaygıları. Education Sciences (NWSAES), 12(3), 107-121.

Altunkaya, H.ve Erdem, I. (2017). Yabancı dil olarak Türkçe öğrenenlerin okuma kaygıları ve okuduğunu anlama becerileri. Sakarya University Journal of Education, 7(1), 59-77.

Baş, G. (2013). Yabancı dil öğrenme kaygısı ölçeği: geçerlik ve güvenirlik çalışması. Türkiye Sosyal Araştırmalar Dergisi, 17(2), 49-68.

Batumlu, D. Z. ve Erden, M. (2007). Yıldız teknik üniversitesi yabancı diller yüksekokulu hazırlık öğrencilerinin yabancı dil kaygıları ile İngilizce başarıları arasındaki ilişki. Eğitimde Kuram ve Uygulama, 3(1), 24-38.

Boylu, E. ve Çangal, Ö. (2015). Yabancı dil olarak Türkçe öğrenen Bosna-Hersekli öğrencilerin konuşma kaygılarının çeşitli değişkenler açısından incelenmesi. Uluslararası Türkçe Edebiyat Kültür Eğitim Dergisi, 4(1), 349-368.

Cheng, Y, S. (2004). A Measure of second language writing anxiety: scale development and preliminary validation. Journal of Second Language Writing, 13, 313-15.

Creswel, J. W. (2016). Araştırma deseni nitel, nicel ve karma yöntem yaklaşımları. (2. Baskı). (Çev. ed. Selçuk Beşir Demir). Ankara: Eğiten Kitap.

Çalık, M. ve Sözbilir, M. (2014). İçerik analizinin parametreleri. Eğitim ve Bilim, 39(174), 33-38.

Çoban, i. (2013). Orhun Yazıtlarının dilin dört becerisi açısından incelenmesi. Yayımlanmamış Yüksek Lisans Tezi, Atatürk Üniversitesi Eğitim Bilimleri Enstitüsü, Erzurum.

Doğan, S. (1988). Lise öğrencilerinin İngilizce öğrenimlerini etkileyen yabancı dil kaygısı. Dil Dergisi, 139, 48-67.

Erdil, M. (2016). TÖMER' de Türkçe öğrenen yabancı öğrencilerin Türkçe öğrenmeye ilişkin kaygı düzeyleri. Yayımlanmamış Yüksek Lisans Tezi, Çanakkale Onsekiz Mart Üniversitesi Eğitim Bilimleri Enstitüsü, Çanakkale.

Halat, S. (2015). Yabancı dil olarak Türkçe öğrenenlerin dinleme becerisine yönelik kaygı düzeylerinin incelenmesi. Yayımlanmamış Yüksek Lisans Tezi, Gazi Üniversitesi Eğitim Bilimleri Enstitüsü, Ankara.

Horwitz, B. M., Horwitz, K. E. ve Cope, J. (1986). Foreign language classroom anxiety. The Modern Language Journal, 70(2), 125-132.

İşcan, A. (2015). Yabancı dil olarak Türkçe öğretiminde yazma kaygısı üzerine bir inceleme (Ürdün Üniversitesi Örneği). Dil ve Edebiyat Eğitimi Dergisi, 14, 135-152.

Kim, J. (2002). Foreign language listening anxiety: A study of Korean students learning English. Doctoral Dissertation, The University of Texas at Austin, Texas.

Kleinmann, H. H. (1977). Avoidance behavior in adult second language acquisition. Language Learning, 27, 93107.

Maden, S., Dincel, Ö. ve Maden, A. (2015). Türkçeyi yabancı dil olarak öğrenenlerin yazma kaygıları. Uluslararası Türkçe Edebiyat Kültür Eğitim Dergisi, 4(2), 748-769. 
Melanlıoğlu, D. ve Demir, T. (2013). Türkçe öğrenen yabancılar için konuşma kaygısı ölçeğinin Türkçe formunun geçerlik ve güvenirlik çalışması. International Journal of Social Science, 6(3), 389-404.

Norris, J. M., ve Ortega, L. (2007). The future of research synthesis in applied linguistics: Beyond art or science. TESOL Quarterly, 41(4), 805-815.

Özdemir, E. (2013). Türkçeyi yabancı dil olarak öğrenenlerin konuşma kaygılarının kaynakları. Gazi Üniversitesi Eğitim Bilimleri Enstitüsü, Yayımlanmamış Yüksek Lisans Tezi, Ankara.

Polatcan, F. (2016). Türkçeyi yabancı dil olarak öğrenenlerin yazma kaygılarının incelenmesi. Route Educational and Social Science Journal, 3(3), 1-13.

Polatcan, F. (2018). Yabancı dil olarak Türkçe öğrenenlerin iletişim kurma istekliliklerinin incelenmesi. Yayımlanmamış Doktora Tezi, Atatürk Üniversitesi Eğitim Bilimleri Enstitüsü, Erzurum.

Rashid, A. W. (2017). Yabancı dil olarak Türkçe öğrenen Afgan öğrencilerin konuşma kaygılarının incelenmesi. Yayımlanmamış Yüksek Lisans Tezi, Dokuz Eylül Üniversitesi Eğitim Bilimleri Enstitüsü, İzmir.

Sallabaş, M. E. (2012). Türkçeyi yabancı dil olarak öğrenenlerin konuşma kaygılarının değerlendirilmesi. Turkish Studies - International Periodical For The Languages, Literature and History of Turkish or Turkic. 7(3), 2199-2218.

Sarıgül, H. (2000). Trait anxiety and foreign language anxiety and their effects on learners' foreign language proficiency and achievment. Yayınlanmamış Yüksek Lisans Tezi, Boğaziçi Üniversitesi Sosyal Bilimler Enstitüsü, İstanbul:

Sparks, R. L. ve Ganschow, L. (1991). Foreign language learning differences: affective or native language aptitude differences? The Modern Language Journal, 75, 3-16.

Şahin, N. (2012). Maniheist ve Budist Uygur şiirinin dilin dört temel becerisi açısından incelenmesi. Yayımlanmamış Yüksek Lisans Tezi, Atatürk Üniversitesi Eğitim Bilimleri Enstitüsü, Erzurum.

Şen, Ü. ve Boylu, E. (2015). Türkçeyi yabancı dil olarak öğrenen İranlı öğrencilerin konuşma kaygılarının değerlendirilmesi. Mustafa Kemal Üniversitesi Sosyal Bilimler Enstitüsü Dergisi, 12(30), 13-25.

TDK. (2011). Türkçe sözlük. Ankara: Türk Dil Kurumu Yayınları.

Welch, S. K. (2008). Metasynthesis of the transition from novice to expert: Can Instructional interventions shorten the process?. Yayımlanmamış Doktora Tezi, Capella University, Minnesota.

Yoğurtçu, K. ve Yoğurtçu, G. (2013). Yabancı dil olarak Türkçenin öğreniminde kaygının akademik başarıya etkisi. Adıyaman Üniversitesi Sosyal Bilimler Enstitüsü Dergisi Türkçenin Eğitimi Öğretimi Özel Sayısı, 6(11), 1308-9196.

\section{Extended Abstract}

\section{Introduction}

Turkish has been learned as a foreign language by the societies due to trade, wars, missionary activities for religious purposes etc. throughout the history. Today, with the support of the state, Turkish is being taught to foreigners in a more modern sense. With the help of language centers of universities in Turkey, Yunus Emre Institute, Ministry of Education, Turkish Maarif Foundation and several departments of Turcology in foreign universities abroad, Turkish language and culture are taught. There are many factors that affect the learning process of Turkish learners. One of these factors is anxiety (Erdil, 2016; Halat, 2015; Özdemir, 2013; Rashid, 2017).

\section{Method}

In this research, meta synthesis of content analysis methods was used. Meta synthesis is an interpretive method based on the general characteristics of researches on a subject. Meta synthesis enables researchers and teachers who cannot reach researches, have heavy workloads and cannot follow the emerging topics in educational researches to get an opportunity to follow these researches (Çalık and Sözbilir, 2014: 3436). Meta synthesis allows the integration of ideas and themes, based on the results of individual research (Welch, 2008). In this research, meta synthesis was used since it was aimed to analyze kinds of tendency that studies on anxiety levels of Turkish language learners conducted by Turkish researchers possess, by using 
qualitative methods. According to Norris and Ortega (2007), three features should be included in meta synthesis studies for them to be systematic:

- Criteria must be clearly specified for the selection of studies.

- Research findings should not be evaluated in general. The findings obtained from each study should be separately evaluated.

-The coding list should be made in order to evaluate the research.

An evaluation form was prepared to compile data, based on the research criteria. In this form, the data was analyzed by the researcher. The studies were registered into a computer environment and coded as Ç1, Ç2, Ç3.... Ç20. In the next part, it was classified into categories according to the types of publications, types of studies by language skills, methods and patterns, sample distributions, measurement tools, demographic variables, suggestions for researchers and practitioners. In the third part, mutual themes are identified by making evaluations. The studies were coded by two coders according to the prepared criteria form. At the final part, the forms were combined to generate a common form.

\section{Result and Discussion}

In this study, it was aimed to analyze the researches on the concept of anxiety in teaching Turkish to foreigners in terms of their content. While examining these researches, suggestions to the researchers and practitioners were revealed as a result of the distribution of the research according to the language skills, methods and patterns, samples, measurement tools, demographic variables, qualitative themes and themes.

It was observed that the researches were mostly about speaking (f: 8) skills. It can be said that researches were mostly related to speaking skills since language learning is often associated with speaking skills. In addition, studies on the historical sources of Turkish (Çoban, 2013; Şahin, 2012) determined that the number of concept signs related to speaking language skills were higher. By looking at these results, it can be said that the Turkish nation uses speaking skills more and attach more significance to it than other skills.

In most studies, quantitative (f: 15$)$ research methods were applied. The number of studies conducted with qualitative ( $f: 1$ ) and mixed ( $f: 5)$ methods was found to be insufficient. It can be said that the quantitative research is applied more because of the generalizability of the research. Cresswell (2016) emphasized that quantitative methods were frequently applied since the findings of the research could be used with numerical data.

In the researches about the anxiety levels of Turkish learners as a foreign language, many suggestions made in order to create situations in which the target language can be used in daily life were as follow: to be considered as a fact in the education process, to revise the environment accordingly, to eliminate the anxieties of students by conducting various in-class activities and to pay attention to their level of interest and motivation. Suggestions made in terms of examining the different linguistic skills of Turkish language learners as a foreign language were as follow: to make researches on the anxiety level and to offer solutions about this problem, and to examine the issues of speaking anxiety. In the light of these results, the following suggestions can be made for the researchers:

- It was understood that quantitative research is dominant, and qualitative and mixed research were not sufficiently carried out in the researches about the anxiety status of Turkish learners as a foreign language. In addition to quantitative research, qualitative research can also be carried out.

- Researches were mostly related to speaking and reading language skills. Further studies on writing and listening skills can be carried out. 